\title{
Chromosomal Abnormalities in Myelodysplastic Syndromes Detected With Multiplex Ligation Dependent Probe Amplification
}

\author{
T.Sotirova ${ }^{1}$, S.Genadieva-Stavric ${ }^{1}$, S.Krstevska-Balkanov ${ }^{1}$, A.Dimovski ${ }^{2}$, \\ A.Eftimov ${ }^{2}$, D.Spasovski ${ }^{3}$ \\ ${ }^{1}$ Univesity Clinic of Hematology, Ss. "Cyril and Methodius" University, Macedonia \\ ${ }^{2}$ Faculty of Pharmacy, Ss. "Cyril and Methodius" University, Macedonia \\ ${ }^{3}$ Univesity Clinic Of Reumatology, Ss. "Cyril and Methodius" University, Macedonia
}

\begin{abstract}
Detection of chromosomal abnormalities in myelodysplastic syndromes enables classification according to WHO Classification and risk stratification according to IPSS and R-IPSS, providing physicians with data regarding personal therapy approach. Detection of the chromosomal abnormalities in our cohort study was performed with the method Multiplex Ligation-dependent Probe Amplification is similar to multiplex PCR reactions, but in this case the target-sequences are amplificated, but MLPA probes hybridized for them. 70 patients, chromosomal abnormalities were detected in $32.9 \%$ patients, while $67.1 \%$ patients had normal findings. Patients were classified according to WHO and stratified according to IPSS and R-IPSS. Data obtained enabled us to make treatment strategy at diagnosis. There are different treatment options for different risk groups including allogeneic transplantation for high and very high risk patients as well as hypomethylating agents for those who are not candidates for transplantation. For low risk groups supportive treatment and growing factors were most often the choice. We can conclude that MLPA reliable method for detection of chromosomal abnormalities in myelodysplastic syndromes.
\end{abstract}

Keywords : chromosomal abnormalities, myelodysplastic syndromes, MLPA

\section{Introduction}

Myelodysplastic syndromes are heterogeneous group of diseases, with cytopenias as a result of an ineffective hematopoiesis and dysplastic morphological characteristics in one or more of the cell lines, and an increased risk of progression in acute myeloid leukemia (1).

Classical cytogenetics (karyotype) was a gold standard for a long periodof time for detection of chromosomal abnormalities. But, it was introduced in the late fifties. Meanwhile, a lot of other methods were used such as FISH, PCR based methods and sequencing techniques. Multiplex Ligation-dependent Probe Amplification (MLPA) is a molecular method similar to multiplex PCR reactions. Detection of chromosomal abnormalities in myelodysplastic syndromes (MDS) is of great importance both for classification of patients according to FAB (2) and WHO (3) and stratification according to IPSS (4) and IPSS-R (5). It enables physicians to make personal therapy aproach according to the NCCN Guidelines (6).

\section{Aim Of The Study Study}

The aim of the study was refinement of the diagnosis of patients with MDS by introduction of the molecular cytogenetic analysis 'Multiplex ligation-dependent probe amplification' (MLPA) for detection of chromosomal abnormalities, enabling contemporary classification, prognostic risk stratification, and personalized therapy for MDS patients.

\section{Material And Methods}

Our cohort consisted of 70 adult patients (>18 years), 33 women (47.1\%) and 37 men (52.9\%), 66 pts with 'de-novo' and 4 pts with therapy-related MDS (t- MDS), diagnosed at the University Clinic of Hematology, "Ss Cyril and Methodius" University, Skopje, Macedonia, from January 2011 till April 2015, with the follow up period of 52 months. Diagnosis was based on the criteria according to the recommendations of the International Consensus Working Group from 2007 (7). Patients signed informed consent for entrance in the study. Statistical analysis was performed with statistical programs STATISTICA 7.1 and SPSS 17.0.

\subsection{Collection Of Material And DNA Isolation}

We collected $1 \mathrm{~mL}$ of bone marrow aspirate from each patient and put in the test tube with an anticoagulant $-\mathrm{K}_{3}$ EDTA. Deoxyribonucleic acid (DNA) was isolated with standard phenol chloroform extraction in the Faculty of Pharmacy, Department of biomolecular sciences, Skopje, Macedonia. The material 
was centrifuged at $3000 \mathrm{rpm}, 4^{\circ} \mathrm{C}, 5 \mathrm{~min}$. The watery upper layer was decanted, and the precipitated cells were washed with $0.9 \% \mathrm{NaCl}$, and later washed with lysed solution $\left(1.55 \mathrm{M} \mathrm{NH}_{4} \mathrm{Cl}, 0.1 \mathrm{M} \mathrm{NH}_{4} \mathrm{HCO}_{3}\right.$ and $1 \mathrm{mM}$ EDTA $\mathrm{Ph} 7.4$, final concentration), centrifuged at $3000 \mathrm{rpm}, 4^{\circ} \mathrm{C}, 5 \mathrm{~min}$, in order to lyse the rest of red cells. The rest of the other cells were digested over night at $37^{\circ} \mathrm{C}$ with $0.1 \mathrm{M} \mathrm{NaCl}, 0.05 \mathrm{M}$ Tris, $1 \mathrm{mM}$ EDTA in final concentration. The next day fluid-fluid extraction was performed with saturated phenol $(\mathrm{pH}=8)$ and Chloroform : Isoamyl alcohol 24:1, after centrifugation at $3000 \mathrm{rpm}, 4^{\circ} \mathrm{C}, 5 \mathrm{~min}$. and removal of the upper watery layer, the precipitation of the DNA with cold 100\% ethanol was performed and dissolved with TE puffer (Tris $10 \mathrm{mM}$ и EDTA $1 \mathrm{mM}$, final concentration). The isolated DNA was incubated overnight on $37^{\circ} \mathrm{C}$ for homogeneous dissolution in the puffer. The intactness of the isolated DNA was examined on gel electrophoresis. With NanoDrop 2000 spectrophotometer (Thermo Scientific) was determined the concentration of the isolated DNAs.

\subsection{MLPA Analysis}

MLPA is a multiplex polymerase chain reaction (PCR)-based technique that can quantify up to 50 different genomic targets simultaneously in a single experiment through amplification of specific hybridizing probes (8). As the sequence recognized by an MLPA probe is only 50-70 nucleotides long, this assay

is very useful for detection of deletions or amplifications of single exons (9). One of the major advantages is the high specificity of MLPA, because this method is able to distinguish sequences differing in length by only one nucleotide. Another advantage is the low amount of input DNA (minimum of 20-50 ng) required for a successful MLPA reaction (9). Up to 40-50 small specific probes are directed at DNA regions of interest and to reference regions not associated with the disease, providing a resolution greater than FISH or BAC - based aCGH (10). Each probe consists of two oligonucleotides (5'and 3'end-probes), that hybridize to adjacent sites of the target sequence. The short oligonucleotide contains a target-specific sequence and a universal PCR primer X. The long probe consists of a target-specific sequence, a universal PCR primer Y and a stuffer sequence of variable length in between (19-370 nucleotides) to generate the size differences necessary for electrophoretic resolution $(9,11)$. The MLPA reaction comprises five steps and requires a thermocycler and automated genetic analyzer for fragment analysis by capillary electrophoresis. A crucial step of the MLPA assay, especially when used in the diagnostic setting. Screening of big gene deletions/duplications on different chromosome regions such as: 3, 5q (EGR1, MIR145, SPARC, MIR146A), 7q (EZH2), 8q (MYC), 11q (KMT2A), 12p (ETV6), 17 (TP53, NF1, SUZ12), 19, 20p (ASXL1) и Y. Analyses were performed with the application of P414-A1 MDS MLPA kits of MRC Holland, according to their protocol. The most widely used is the Coffalyser software, an Excel-based program able to perform data normalization steps and necessary corrections $(12,13)$. The utility of MLPA assay in the testing of acute leukemias and myelodysplastic syndromes has been analyzed, confirming excellent accuracy and specificity of MLPA as compared to FISH (14). MDS MLPA assay is sufficiently specific and reproducible to be used in routine diagnostic settings as the first-line genetic screening too.

\section{Results}

Of 70 patients, 33 women $(47.1 \%)$ and 37 men $(52.9 \%)$ participated in the study, aged 64.3 years (range 22-86 years). Chromosomal abnormalities were detected in $32.9 \%$ patients, while $67.1 \%$ patients had normal findings (Table 1).

According to FAB Classification 39 pts(55.7\%) belong to the subtype refractory anemia (RA), 2 pts $(2.9 \%)$ to refractory anemia with ring sideroblasts (RARS), 13 pts $(18.5 \%)$ to refractory anemia with excess of blasts (RAEB), 6 pts $(8.6 \%)$ to to refractory anemia with excess of blasts in transformation (RAEB-t), 6 pts $(8.6 \%)$ in chronic myelomonocytic leukemia (CMML) and 4 pts $(5.9 \%)$ in t-MDS. According to WHO olmost half of the patients, 34 pts $(48.6 \%)$ to the subtype refractory cytopenia with unilineage dysplasia, 2 pts $(2.9 \%)$ to $5 \mathrm{q}$ syndrome, $5 \mathrm{pts}(7.9 \%)$ to refractory cytopenia with multilineage dysplasia, $1 \mathrm{pts}(1.4 \$)$ to RARS, 6 pts (8.6\%) to RAEB-1, 6 pts (8.6\%) to RAEB-2, 2 pts (2.9\%) to CMML-1, 3 pts (4.3\%) to CMML-2, 4 pts $(5.7 \%)$ to t-MDS, and $1 \mathrm{pts}(1.4 \%)$ to unspecified MDS (u-MDS).

Table.1 Chromosomal abnormalities in our cohort

\begin{tabular}{|l|l|l|}
\hline Chomosomal abnormalities & Number & $\%$ \\
\hline Normal finding & 47 & 67.1 \\
\hline $5 \mathrm{q}-, 7 \mathrm{q}-, 12 \mathrm{p}-, 17 \mathrm{p}-, 19 \mathrm{p}+$ & 1 & 1.4 \\
\hline+8 & 2 & 2.9 \\
\hline $12 \mathrm{p}-$ & 2 & 2.9 \\
\hline $5 \mathrm{q}-$ & 2 & 2.9 \\
\hline $11 \mathrm{p}-$ & 1 & 1.4 \\
\hline $5 \mathrm{q}-, 7 \mathrm{q}-$ & 2 & 2.9 \\
\hline $5 \mathrm{q}-, 7 \mathrm{q}-, 17 \mathrm{p}-$ & 1 & 1.4 \\
\hline $19 \mathrm{p}-$ & 1 & 1.4 \\
\hline $7 \mathrm{q}-, 20 \mathrm{q}-$ & 1 & 1.4 \\
\hline
\end{tabular}




\begin{tabular}{|c|l|l|}
\hline $5 \mathrm{q}-, 12 \mathrm{p}-$ & 1 & 1.4 \\
\hline $5 \mathrm{q}-, 8 \mathrm{q}-$ & 1 & 1.4 \\
\hline $\mathrm{Yp}-$ & 2 & 2.9 \\
\hline $\mathrm{t}(3 ; 3)(\mathrm{q} 21, \mathrm{q} 26)$ & 1 & 1.4 \\
\hline $5 \mathrm{p}+, 5 \mathrm{q}-, 7 \mathrm{p}-, 7 \mathrm{q}-, 8 \mathrm{p}+, 8 \mathrm{q}+, 12 \mathrm{p}-$, & 1 & 1.4 \\
$19 \mathrm{p}+$ & & \\
\hline $17 \mathrm{p}-, 17 \mathrm{q}+$ & 1 & 1.4 \\
\hline $20 \mathrm{q}-$ & 1 & 1.4 \\
\hline inv(9)(p12q13) & 1 & 1.4 \\
\hline+9 & 1 & 1.4 \\
\hline Total & 70 & 100.0 \\
\hline
\end{tabular}

According to IPSS, distribution was as follows: low risk - 16 patients (22.9\%), intermediate $1-37$ (52.9\%), intermediate $2-8(11.3 \%)$ and high risk - 9 (12.9) (Table 2).

Table.2. Risk Stratification according to IPSS

\begin{tabular}{|l|l|l|}
\hline IPSS & Number & $\%$ \\
\hline Low risk & 16 & 22.9 \\
\hline Intermediate-1 risk & 37 & 52.9 \\
\hline Intermediate-2 risk & 8 & 11.3 \\
\hline High risk & 9 & 12.9 \\
\hline Tortal & 70 & 100.0 \\
\hline
\end{tabular}

According to R-IPSS, distribution was as follows: very low risk - 5 (7.1\%), low risk $22(31.4 \%)$, intermediate risk - 24 (34.3\%), high risk - $10(14.3 \%)$ and very high risk - 9 (12.9\%) patients. (Table 3$)$

Table.3. Risk Stratification according to IPSS-R

\begin{tabular}{|l|l|l|}
\hline R-IPSS & Number & $\%$ \\
\hline Very low risk & 5 & 7.1 \\
\hline Low risk & 22 & 31.4 \\
\hline Intermediate risk & 24 & 34.3 \\
\hline High risk & 10 & 14.3 \\
\hline Very high risk & 9 & 12.9 \\
\hline Total & 70 & 100.0 \\
\hline
\end{tabular}

There are different treatment options for different risk groups including allogeneic transplantation for high and very high risk patients as well as hypomethylating agents for those who are not candidates for transplantation. In our cohort allogeneic transplantation was performed in 4 pts (5.7\%). Azacitidine received only one patient $(1.4 \%)$. Chemotherapy received $20 \%$ of pts.

For low risk groups supportive treatment and growing factors were the choice. Packed red blood cells (PRBCs) received 44 pts, $<18$ units received 33pts (47.1\%), while > 18 units received 11pts $(11.7 \%)$. Erythropoietin was given in 10\% of pts, while Granulocyte-Colony Stymulating Factor was given in 17,1\%. Immunosupressive therapy received $30 \%$ of pts. Chelating agents were given in $8.6 \%$ of pts.

\section{Conclusion}

Data obtained from detection of chromosomal abnormalities are very important because they enable physicians to make treatment strategy at diagnosis. We can conclude from this study that MLPA is reliable method for detection of chromosomal abnormalities in MDS. It ought to be mentioned that there is still a significant percentage of patients with normal findings of chromosome analysis. Despite, they are heterogeneous and belong to different FAB and WHO subtypes and different prognosis according to I PSS and R - IPSS. Therefore, the researches lately are focused on gene mutations, aiming to detect mutations with impact on prognosis. That would lead to their incorporation in prognostic systems, enabling refinement of patient's risk stratification. Due to population, and especially economic reasons, such researches are possible only in developed countries.

\section{References}

[1]. Flandrin G. Classification of myelodysplastic syndromes, Atlas Genet Cytogenet Oncol Haematol. May 2002.

[2]. Bennett JM, Catovsky D, Daniel MT, et al. Proposals for the classification of the myelodysplastic syndromes. Br J Haematol. 1982; 51:189-199.

[3]. Vardiman JW, Thiele J, Arber DA, et al. The 2008 revision of the World Health Organization [WHO] classification of myeloid neoplasms and acute leukemia: rationale and important changes. Blood 2009; 114:937-951.

[4]. 233. Greenberg P, Cox C, LeBeau MM, Fenaux P, Morel P, Sanz G, Sanz M, Vallespi T, Hamblin T, Oscier D, Ohyashiki K, Toyama K, Aul C, Mufti G, Bennett J. International scoring system for evaluating prognosis in myelodysplastic syndromes. Blood. 1997; 89: 2079-2088. 
[5]. 238. Greenberg PL, Tuechler H, Schanz J, Sanz G, Garcia-Manero G, Solé F, Bennett JM, Bowen D, Fenaux P, Dreyfus F, Kantarjian H, Kuendgen A, Levis A,Malcovati L, Cazzola M, Cermak J, Fonatsch C, Le Beau MM, Slovak ML, Krieger O, Luebbert M, Maciejewski J, Magalhaes SM, Miyazaki Y, Pfeilstöcker M,Sekeres M, Sperr WR, Stauder R, Tauro S, Valent P, Vallespi T, van de Loosdrecht AA, Germing U, Haase D. Revised international prognostic scoring system for myelodysplastic syndromes. Blood. 2012; 120(12):2454-65.

[6]. https://www.google.com/\#q=nccn+guidelines+myelodysplastic+syndromes+2016

[7]. Mufti GJ, Bennett JM, Goasguen J, et al. Diagnosis and classification of myelodysplastic syndrome: International Working Group on Morphology of myelodysplastic syndrome (IWGM-MDS) consensus proposals for the definition and enumeration of myeloblasts and ring sideroblasts. Haematologica 2008; 93:1712.

[8]. Fabris S, Scarciolla O, Morabito F, Cifarelli RA, Dininno C, Cutrona G, Matis S, Recchia AG, Gentile M, Ciceri G, Ferrarini M, Ciancio A, Mannarella C, Neri A, Fragasso A. Multiplex ligation-dependent probe amplification and fluorescence in situ hybridization to detect chromosomal abnormalities in chronic lymphocytic leukemia: a comparative study. Genes Chromosomes Cancer 2011;50:726-34.

[9]. Schouten JP, McElgunn CJ, Waaijer R, Zwijnenburg D, Diepvens F, Pals G. Relative quantification of 40 nucleic acid sequences by multiplex ligation-dependent probe amplification. Nucleic Acids Res 2002;30:e57

[10]. Donahue AC, Abdool AK, Gaur R, Wohlgemuth JG, Yeh CH. Multiplexligation-dependent probe amplification for detection of chromosomal abnormalities in myelodysplastic syndrome and acute myeloid leukemia. Leuk Res 2011;35:1477-83.

[11]. Sellner LN, Taylor GR. MLPA and MAPH: new techniques for detectionof gene deletions. Hum Mutat 2004;23:413-9.

[12]. Jankowski S, Currie-Fraser E, Xu L, Coffa J. Multiplex ligation-dependent probe amplification analysis on capillary electrophoresis instruments for a rapid gene copy number study. J Biomol Tech 2008;19:238-43.

[13]. Coffa J, van de Wiel MA, Diosdado B, Carvalho B, Schouten J, Meijer GA. MLPAnalyzer: data analysis tool for reliable automated normalization of MLPA fragment data. Cell Oncol 2008;30:323-35.

[14]. Stuppia L, Antonucci I, Palka G, Gatta V. Use of the MLPA Assay in the Molecular Diagnosis of Gene Copy Number Alterations in Human Genetic Diseases. Int J Mol Sci 2012;13:3245-76. 